Holmes \& Lindley have argued the need within the NHS to adapt psychoanalytic techniques and values in order to reach the people most in need of psychotherapy. Training at senior registrar level should encourage initiative in tackling this issue.

Finally, the duties of a consultant psychotherapist are more likely to be approached flexibly and humanely by someone with life experience and interest in things outside the psychotherapeutic sphere than by the highly trained practitioner who has not had time to read, listen to music, dig the garden or chat with friends.

Graylingwell Hospital

SOPHIA HARTLAND Chichester PO194PQ

\section{What would you have done?}

DeAr Sirs

The letter from Drs Joyce \& Palia (Psychiatric Bulletin, 1992, 16, 52) reminded me that some years ago an elderly patient continuously and agonisingly screeched, causing great distress in a 25-bedded ward. Her teeth were very carious and the gums infected. She was too demented to give real consent to treatment and her husband, likening dentists and surgeons to butchers, was opposed to treatment. I consulted a member of my medical defence society and he said that if a senior psychiatric consultant colleague, the dentist and I all signed to the effect that we considered dental treatment essential we could go ahead with it. We did so and the result was pleasing to all concerned, including the husband, who bore no resentment.

Joyce \& Palia's patient, not knowing her age or the year, month, season, day or the name or the nature of the place she was in and not remembering having been told she had a stone in her bladder, seems incapable of giving consent to essential treatment and, although questions of consent have become more complicated in recent years, perhaps Joyce and Palia would consider following the same procedure as I did, presumably substituting the appropriate health authority solicitor for the medical defence society.

Fulford Grange Hospital

GeOfFrey Wallis

Micklefield Lane Rawdon

Leeds LS196BA

\section{The standard Eire and other deviations}

Dear Sirs

Professor Fahy (Psychiatric Bulletin, February 1992, $16,113)$ is, of course, quite right: the English name of our homeland is Ireland. However, an ethnic error, if deliberate, can sometimes help to prevent a postal one. Just as mail addressed to Basel, Switzerland, from the United States is not infrequently routed via Brazil or Sweden, whence it may arrive after some delay, mail for Ireland, even if posted in Boston, can take longer to arrive than expected. The "Defensive Strategy", discouraged by Professor Fahy, of insisting that Ireland is a Republic does not always help, for Iceland is a republic as well. But if at least the purveyors of junk mail originating in America were encouraged to locate Dublin (and even Galway) in Eire, their products would be unlikely to be forwarded at all from Zaire.

Psychiatric University Policlinic

C. R. B. JOYCE 3010 Bern.

Switzerland

\section{Resettlement of long-stay patients in the community}

DeAR SirS

We would like to comment on Double \& Wong's (Psychiatric Bulletin, 1991, 15, 735-736) follow-up study of patients resident in Middlewood Hospital on 12 January, 1982.

In general, their findings must give grounds for cautious optimism regarding the resettlement of long-stay patients in the community in Sheffield, although we doubt that there is reason for complacency. HRH Prince of Wales (1991) has succinctly outlined the large gaps that still exist in our knowledge regarding the impact of deinstitutionalisation.

The authors assert that they found no homelessness in their follow-up study of discharged long-stay patients: yet two patients were found to be resident in the Sheffield hostel for homeless men. It is possible that by using such a narrow definition of homelessness (i.e. rooflessness) the authors have underestimated the extent of the problem.

The authors state that studies on community care should distinguish between the needs of acute patients and those of the long stay. This is clearly true. A recent study (Meltzer et al, 1991) drew attention to the impoverished social circumstances of acute psychiatric patients discharged to the community and suggested that the priority given to the resettlement of long-stay patients into supported accommodation is depriving the former group of adequate community care. In support of this, George et al (1991) found high rates of recent psychiatric hospitalisation in a census of single homeless people in Sheffield.

We suggest that in their efforts to counter the "poorly reasoned polemic" of others, Double \& Wong are tilting at windmills: it would be unfortunate if such controversies distracted attention away 